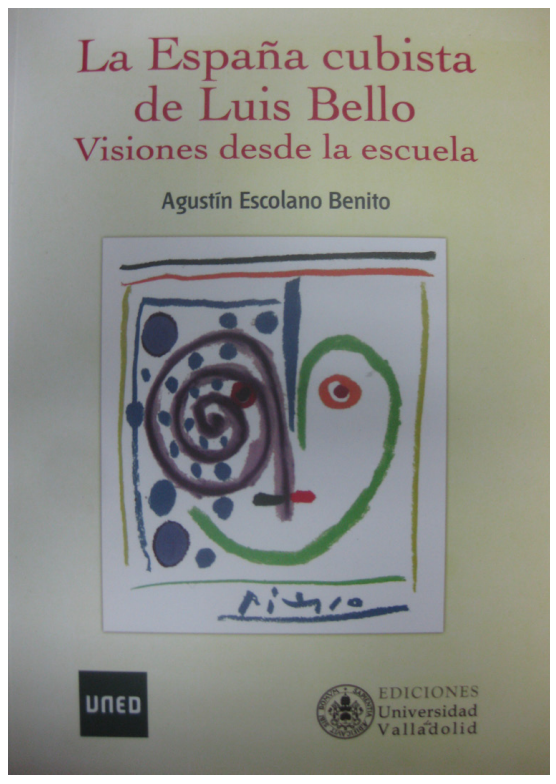

ESCOLANO BENITO, A. (2014): La España cubista de Luis Bello. Visiones desde la escuela. Valladolid: Ediciones de la Universidad e UNED, 240 pp.

!Cuantas Españas hay!

Podriamos llegar a entendernos con las diversas

Españas;

ir dándoles la vuelta

para ver donde tienen unas con otras su ensamblaje, $o$ ir penetrando en ellas profundamente para hallar que el fondo es el mismo. Luis Bello,

1926.

O xornalista e político republicano liberal reformista é recoñecido como unha das figuras de maior prestixio social e cultural na vida española dos anos vinte-trinta, por querer construír unha sociedade democrática presidida por un alto civismo, e por suscitar unha elevada conciencia social sobre o papel que nesa construción lle debería corresponder á escola pública como espazo cultural máis propicio para levar a cabo tal construción; o espazo de socialización cultural das maiorías sociais.

A tal fin e coa convición do estado deficiente desa escola no conxunto das terras de España, Luís Bello procedeu a un exame empírico, para o que percorreu ao longo dos anos 1925-1929 unha grande parte desas terras, de Andalucía a Cataluña, de Madrid a Extremadura, de Asturias a Galicia, o que lle permitiu comprobar !Cuantas Españas hay!, ao tempo que ía facendo un diagnóstico certamente crítico da realidade escolar que observaba, non exento a contrario de felices realidades escolares (en todo caso, unha menor parte) e de figuras de mestres e mestras nas que cabía confiar plenamente cara esa escola de todos, culturalmente afirmada e impregnada de sentido cívico.

Como sabemos, aquelas viaxes foron conformando na pluma do xornalista as súas columnas de textos "Visitas de escuelas" publicadas, as veces día si e día tamén, nas recoñecidas páxinas de El Sol, antes de pasar a configurarse en catro tomos de Viajes por las Escuelas de España, co apéndice posterior Viajes por las Escuelas de Galicia (mediante as edicións de Gonzalo Anaya e a máis recente de Antón Costa). A partir de 1905 e ata 2003 o profesor Agustín Escolano precedeu a reedición anotada de case todos aqueles textos en cinco edicións, procurando dar a coñecer e interpretar historicamente a obra de Luís Bello.

A case 20 anos da primeira das reedicións realizadas, Escolano realiza unha nova observación ${ }^{1}$ dos textos e das reflexións de Luis Bello, que falaba da uni-

${ }^{1}$ A presente edición contou co apoio editorial da UNED, na serie MANES, dirixida pola profesora 
dade/diversidade de España, das súas terras, pobos e xentes (unha "España cubista"), en contraste, poderiamos dicir, con outros textos (fundamentalmente manuais escolares do primeiro terzo do século XX editados en distintos escenarios españois e que procuraban trasladar en distinto grao e modo aos escolares imaxes e representacións da unidade/diversidade), mediante un excelente texto de historia da educación, rico en imaxes comentadas, onde se dan cita o moi considerable coñecemento da historiografía xeral española relativa aos século XX, a comparación histórica, a historia socio-cultural, a historia do currículo, un consistente aparato crítico, a análise de numerosas e diversas fontes (falamos dos manuais e libros de texto non examinados ata o presente dese modo contrastado), a finura interpretativa e un depurado estilo literario.

O texto, con presentación de Cesar Antonio Molina, abre cunha introdución ("La mirada de Bello sobre España"), que da paso á Primeira parte, "La España cubista de Bello" (un 'xogo' para proceder a descompoñer e a recompoñer España), onde Agustin Escolano analiza o conxunto dos textos escritos por Bello presentándonos a súa comprensión de España; as súas imaxes en relación as terras, pobos e xentes que visita e recorre, desde a concordia, a converxencia e o sentimento de harmonía, probablemente 'un pouco a au dessous de la melée' e prescindindo de reais, sociolóxicas e estruturais zonas de conflito económico, social, político ou cultural; e como Bello pensaba orteguianamente a reconstrución dunha España de todos. Así se desprende dalgúns dos epígrafes: "Ou-

Gabriela Ossenbach, actualmente Presidenta da Sociedade Española de Historia da Educación. tra cartografía da nación", "Da paisaxe á etnografía", "Vertebración e concordia", ou "España, unha Minerva nacional"

A Segunda Parte ("La imagen de España en la cultura y en la escuela") examina a imaxe de España e tamén as de Cataluña, do País Vasco e de Galicia que se desprenden dos manuais escolares presentes nas escolas españolas durante o primeiro terzo do século XX, fose nas escolas de Madrid, nas de Barcelona, nas de Bilbao ou as de Santiago de Compostela, tendo en conta a presenza de diversos autores e de edicións, que en casos poderíamos chamar 'locais' (Grandezas de España, Estampas de España, Antologia Catalana, El auxiliar del maestro catalán, Historia de Catalunya. Curs Mitjà, Llibre dels infants, Xabiertxo, Euskal Liburu Sorta, Txomin Ikasle, Lecturas vascongadas, Nova Xeografía de Galicia pras escolas, Lecturas escolares). Dos diversos textos despréndense diversas imaxes de España e das distintas terras: obsérvase a forte emerxencia da cultura catalana (pp. 97-135), o sentimento de Euskadi como patria dos vascos (pp. 136 a 156), ou o binomio tradición-rexurdimento no caso galego (pp. 158-175), así como tamén a abundancia de estereotipos, tanto rexionais como "nacionais" (pp. 175 a 216), que Escolano examina con detallada atención. España sería, para uns, un xardín patriótico; para outros, un "viveiro de nacións".

Termina Agustín Escolano cunhas consideracións finais ("España, espacio común compartido") en que se examinan as representacións pictóricas de Sorolla e as de Picasso: diferentes as dúas aínda sendo favorables á observación das diversidade. Alén da imaxe da xustaposición de 'identidades rexionais' nun marco nacional común, tamén o profesor Escolano se aco- 
lle a unha visión máis complexa, a proposta polo cubismo da que falara Bello, probablemente máis relativista, pero formulada desde un novo e reconstrutivo ensamblaxe de España e desde un desexable horizonte de porvir inclusivo e solidario.

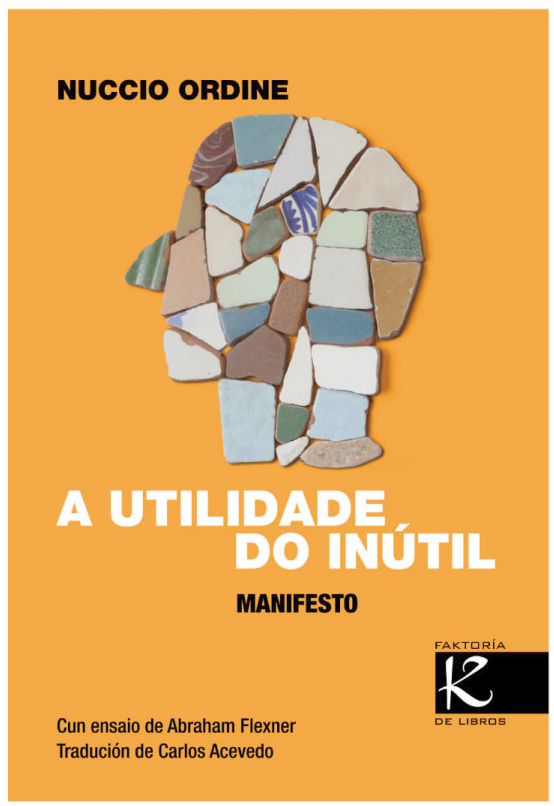

ORDINE, Nuccio (2015): $A$ utilidade do inútil. Pontevedra: Ed. Kalandraka.

Sabemos que hai palabras-clave, palabrascume que condensan as nosas ideas, as nosas esperanzas e as nosas decisións, e que deberían brillar como estrelas mentais cada vez que as pronunciemos. Sabemos moi ben cales son esas palabras nas que se centran tantas obrigas e tantos desexos: liberdade, dignidade, dereitos humanos, pobo, xustiza social, democracia, entre outras moitas (...).
Mais, pouco a pouco as palabras viciáronse, enfermaron a por de ser violadas polas peores demagoxias da linguaxe dominante. $E$ nós que as amamos porque nelas alenta a nosa verdade, a nosa esperanza e a nosa loita, seguimos decíndoas porque as necesitamos, porque son as que deben expresar e transmitir os nosos valores positivos, as nosas normas de vida e as nosas consignas de combate. Decímolas, sí, e é necesario e fermoso que así sexa.

Julio Cortázar. "As palabras violadas".

O home necesita en primeiro lugar, como quen bebe auga, beber soños.

\section{Álvaro Cunqueiro}

Por un azar, chegou ás nosas mans un ensaio necesario, cun título de seu moi suxerente: $A$ utilidade do inútil, do profesor italiano Nuccio Ordine. Un ensaio de lectura amable, mais de grande profundidade e rigor. Unha lectura moi grata en canto que 0 autor combina admirablemente a claridade da súa prosa e a amenidade expositiva coa fondura do seu pensamento, nunha simbiose moi efectiva, algo que o lector sempre agradece.

O capítulo inicial do libro leva por título: "A útil inutilidade da literatura". Un título revelador. Moito se ten escrito sobre o valor das humanidades, sobre a súa transcendencia na formación humana e sobre a seu rol e a súa consideración curricular no actual sistema educativo. Temos lidas moitas páxinas ao respecto, moitas veces admirables e clarificadoras, mais outras moitas pouco reveladoras. Por iso louvamos tanto a lectura deste libro, pois poucas veces vimos tan ben tratada esta cuestión obxecto de innumerables controversias. Nun tempo social e educativo no que estamos necesitados de pensamento educativo liberador, as palabras de Nuccio Ordine resúltannos 